\title{
FONTES DE FORMAÇÃO DAS CRENÇAS DE AUTOEFICÁCIA DE DOCENTES DO ENSINO SUPERIOR
}

\author{
Priscile Bernardini, Camélia Santina Murgo \\ Universidade do Oeste Paulista - UNOESTE, Mestrado em Educação, Presidente Prudente, SP. E-mail: \\ prixber1@gmail.com.
}

\begin{abstract}
RESUMO
Este estudo teve como propósito analisar as fontes de formação das crenças de autoeficácia de docentes do ensino superior. Os participantes foram 43 docentes de ensino superior de instituições públicas e privadas do interior do estado de São Paulo. Para avaliara formação das crenças foi utilizada a Escala sobre Fontes de Autoeficácia composta por 16 itens organizados em quatro subescalas, que englobam as quatro fontes fundamentais de influência, a saber, Experiências Vividas, Experiências Vicárias, Persuasão Social e Estados Fisiológicos e Afetivos. Os resultados indicaram que,entre os professores participantes, as fontes Persuasão Social $(M=25,6)$ e Estados Fisiológicos e Afetivos ( $M=17,5)$ são mais determinantes na formação das crenças de autoeficácia. Dada a limitação no numero de participantes e a escassez da produção, são recomendados novos estudos a fim de investigar, junto aos docentes, as fontes formadoras das suas crenças de autoeficácia.

Palavras-chave: autoeficácia; professor; trabalho docente; ensino superior; teoria social cognitiva.

\section{FORMATION OF SOURCES OF SELF-EFFICACY BELIEFS OF PROFESSORS IN HIGHER EDUCATION INSTITUTIONS}

\begin{abstract}
This study aimed to analyze the forming sources of self-efficacy beliefs of professors in higher education institutions. The participants were 43 professors in higher education from public and private institutions in São Paulo State, Brazil. To evaluate the formation of beliefs, this study used the Scale of Self-efficacy Sources consisted of 16 items and organized into four subscales, which include the four fundamental sources of influence: Mastery Experiences, Vicarious Experiences, Social Persuasion and Physiological and Emotional States. The results of the study indicated that the Social Persuasion sources $(M=25.6)$ and the Physiological and Emotional States sources $(M=$ 17.5) are more decisive in the formation of self-efficacy beliefs among the participants. Due to the limited number of participants and the scarcity of production, further studies are needed to investigate the forming sources of self-efficacy beliefs among professors.
\end{abstract}

Keywords: self-efficacy; teacher; teaching work; higher education; social cognitive theory. 


\section{INTRODUÇÃO}

As crenças de autoeficácia têm sido associadas ao êxito pessoal, visto que provavelmente os indivíduos realizarão atividades que acreditam terem mais capacidade de êxito, do que aquelas que creem que tenderão ao fracasso. Na verdade, o ser humano propende a evitar envolver-se em tarefas onde o seu sentido de competência se revela reduzido. Assim, a autoeficácia faz diferença em como as pessoas sentem, pensam e agem e isso reflete nas escolhas, conduta e desempenho.

Albert Bandura, representante expressivo da Teoria Social Cognitiva apresenta um modelo explicativo para os fatores determinantes da ação humana. Mais especificamente, o conceito de autoeficácia docente "seria a crença dos professores em suas próprias capacidades de desempenhar atividades docentes que os levem a atingir os resultados esperados." (Ferreira e Azzi, 2010, p.24).

Já as crenças de autoeficácia, construto também central da Teoria Social Cognitiva, são formadas e alteradas por meio da transmissão de informações e de estratégias de ação para se lidar com situações desafiadoras através de modelos competentes, além da comparação com as conquistas dos outros em situações similares, sendo, segundo Bandura (1999), informações particularmente úteis para o desenvolvimento de habilidades cognitivas.

Contudo, é fundamental se atentar para a importância das quatro fontes de construção das crenças de autoeficácia, iniciando pela elucidação da Experiência Pessoal em tarefas anteriores, fonte que serve como um indicador de habilidade. De acordo com Nunes (2008) tal fonte é manifestada por meio de interpretação de experiências prévias, ou seja, as experiências são usadas para desenvolver ou sustentar crenças sobre a capacidade para se envolver em certas tarefas, que posteriormente deverão influenciar na motivação e persistência para se engajar em tarefas do mesmo domínio.

A Aprendizagem Vicária é apresentada por Nunes (2008) como a fonte que gera as crenças de eficácia por meio da observação das outras pessoas realizando certas ações. Quando se observa pessoas com perfil semelhante realizando tarefas e tendo sucesso, o individuo infere que também possui capacidade de realizá-las da mesma maneira, elevando assim suas crenças de autoeficácia.

Já a fonte Persuasão Verbal, diz respeito aos feedbacks avaliativos sociais recebidos como forma de convencimento de que uma pessoa tem certas competências e servem como meio de fortalecimento das crenças que as pessoas possuem sobre suas próprias capacidades. Sendo assim, "tenta-se convencer as pessoas de que elas têm as habilidades necessárias para alcançar o que buscam, bem como, tenta-se convencer as pessoas da pouca habilidade para a atividade em questão" (Nunes, 2008, p. 35). Dessa maneira, ocorre o aumento ou a diminuição da autoeficácia percebida, já que acreditando nos feedbacks positivos há um aumento dos esforços para realização das tarefas e consequentemente das crenças de autoeficácia. Por outro lado, se a persuasão é negativa, o indivíduo poderá diminuir seus esforços e esquivar-se das atividades desafiadoras.

Por fim, a partir de Indicadores Fisiológicos é possível predizer, de acordo com as reações físicas e emocionais, fatores que sugerem julgamentos quanto à própria capacidade, confiança, força e vulnerabilidade diante de situações desafiadoras. Como ressalta Rocha (2009), os estados fisiológicos influenciam o julgamento que as pessoas fazem de suas próprias capacidades, ou seja, atuam na determinação da sua autoeficácia pessoal, já que estados emocionais, psicológicos e fisiológicos positivos aumentam a autoeficácia percebida, ao contrário de estados negativos, que reduzem a sua autoeficácia. Importante destacar que as fontes não operam separadamente e de forma independente.

Em uma investigação, Rocha (2009) verificou as crenças e as fontes de autoeficácia docente no ensino superior levando em consideração a intencionalidade da ação e o manejo de classe do professor. Também buscou correlações entre crenças e fontes de autoeficácia e variáveis pessoais, 
da atividade e do contexto docente além de objetivar compreender as relações entre as crenças de autoeficácia e as fontes de autoeficácia. Em seu estudo, a autora contou com 457 docentes atuantes em diversas instituições publicas e privadas de ensino superior.

A autora pode constatar que os participantes apresentaram altas tendências nas crenças de autoeficácia tanto na subescala de intencionalidade da ação docente, como na subescala de manejo de classe. No que se refere as relações entre crenças de autoeficácia e variáveis pessoais, da atividade docente e de contexto, os resultados revelaram diferenças significativas quanto ao nível de formação, tempo de atuação, jornada de trabalho, percepção de preparo como docente, satisfação com o trabalho, avaliação da infraestrutura, apoio, recebido na instituição e possibilidades de expressar ideias.

Rocha (2009), ao analisar os dados coletados sobre as fontes de informação de autoeficácia, detectou influencias das experiências diretas, seguida de persuasão social, experiências vicárias e estados fisiológicos e emocionais. Já a análise das relações entre autoeficácia docente e as fontes de autoeficácia mostrou baixa correlação positiva e significativa entre a pontuação média na escala de autoeficácia e escala de fontes de autoeficácia, com exceção da fonte de estados fisiológicos e emocionais.

Sendo assim, este estudo teve como propósito analisar as fontes de formação das crenças de autoeficácia de docentes do ensino superior, visto que a construção das crenças positivas ou negativas depende das influências recebidas das fontes de autoeficácia e isso reflete nas escolhas, conduta e desempenho dos professores.

\section{METODOLOGIA}

Os participantes foram 43 docentes de ensino superior de instituições públicas e privadas do interior do estado de São Paulo. Entre os participantes, 16 eram do sexo masculino e 27 do sexo feminino. A faixa etária ficou compreendida entre 20 e 50 anos. Em relação à escolaridade, 03 docentes tinham Pós-Graduação, 7 com Especialização, 29 com Mestrado e 4 com Doutorado. Quanto ao tempo de formação, 16 docentes eram formados há 05 anos, 20 docentes formados entre 5 a 10 anos, 6 formados entre 11 a 15 anos, 1 docente do sexo masculino formado há mais de 20 anos.

Para analisar as fontes de formação das crenças de autoeficácia de docentes foi utilizada a Escala sobre Fontes de Autoeficácia (laochite e Azzi, 2007), composta por 16 itens organizados em quatro subescalas, que englobam as quatro fontes fundamentais de influência, anunciadas por Bandura (1999). As quatro fontes referem-se a Experiências Diretas (itens 5, 12 e 13), Experiências Vicárias (itens 1, 2 e 6), Persuasão Social (itens 3, 10, 11, 14 e 15) e Estados Fisiológicos e Afetivos (itens $4,7,8,9$ e 16). A escala é do tipo Likert de 1 a 6 pontos, sendo que a pontuação 1 diz respeito a "totalmente falso" e a pontuação 6 à "totalmente verdadeiro".

Quanto aos procedimentos de coleta e análise dos dados, o estudo foi realizado após aprovação no Comitê de Ética em Pesquisa (Protocolo 2249). A aplicação das escalas foi de forma coletiva e o tempo médio para que os participantes respondessem o instrumento foi de 30 minutos. No contato com os participantes, foram esclarecidos os objetivos do estudo e entregue o TCLE (Termo de Consentimento Livre e Esclarecido), sendo os dados coletados analisados quantitativamente.

\section{RESULTADOS}

A aplicação da escala utilizada como instrumento de coleta de dados permitiu conhecer algumas fontes que podem intensificar ou enfraquecer as crenças de autoeficácia. Na aplicação, os professores foram solicitados a indicar o quanto concordavam com a relação entre as afirmativas de cada item e a formação de suas crenças sobre sua capacidade de ensinar, ou seja, sobre sua autoeficácia docente. 
Os itens da escala estão distribuídos em quatro fatores, representativos das fontes de formação de crenças, a saber, Experiências vividas, Experiências Vicárias, Persuasão Social e Estados Fisiológicos e Emocionais. A Tabela 1 mostra os escores mínimo e máximo, bem como as médias dos participantes em cada fator da escala.

Tabela 1. Valores Mínimos, Máximos e Médios nos fatores da Escala Sobre Fontes De Autoeficácia

\begin{tabular}{lcccc}
\hline Fatores & Mínimo & Máximo & Média & DP \\
\hline 1 - Experiências Vividas & 6 & 18 & 14,6 & 2,34 \\
2 - Experiências Vicárias & 7 & 18 & 15,2 & 2,33 \\
3 - Persuasão Social & 17 & 30 & 25,6 & 3.05 \\
$\begin{array}{l}\text { 4-Estados Fisiológicos e } \\
\text { Afetivos }\end{array}$ & 5 & 27 & 17,5 & 5,35 \\
Escala Geral & 46 & 88 & 73,4 & 9,73 \\
\hline
\end{tabular}

Observando-se as médias das respostas dos participantes nos fatores representativos das fontes de informação de autoeficácia, constata-se que foi encontrada menor média nas Experiências Vividas $(M=14,6)$ e maior média na fonte de Persuasão Social $(M=25,6)$. Isso revela que para os professores da amostra, entre as quatro fontes, importa mais o feedback que recebem em relação ao seu trabalho quando se referem a percepção da autoeficácia do que as experiências vivenciadas.

\section{DISCUSSÃO}

Para uma compreensão mais ampliada desses resultados, serão discutidos os resultados referentes aos itens de cada um dos fatores da escala de fontes de autoeficácia. As Experiências Vividas podem ser responsáveis por uma alta percepção de eficácia pessoal quando são bemsucedidas. Ao contrário, os fracassos nessas experiências potencializam percepções de baixa eficácia. Bandura (1997) ressalta que tais percepções resultantes das experiências vividas estão relacionadas não apenas ao desempenho em si numa dada situação ou tarefa, mas também ao processo cognitivo de diagnóstico das informações fornecidas pelo próprio desempenho. Portanto a interpretação feita pela pessoa acerca da situação experienciada pode ser tão determinante quanto a situação em si na formação das crenças.

Quando avaliados os itens da Escala de Fontes de Autoeficácia Docente referentes às Experiências Vividas, mostrou-se mais representativo $(M=5,7)$ para os professores a experimentação de sentimentos positivos durante sua atuação docente (item 12). Esse resultado é igual ao encontrado por Rocha (2009), que ao utilizar a mesma escala num estudo que contou com 457 docentes do Ensino superior pode verificar o mesmo item (12) como o mais enfatizado pelos participantes $(M=5,38)$.

Em outro estudo, Costa Filho e laochite (2015) analisaram 19 documentos, os quais foram produzidos por estudantes em situação de estágio supervisionado de uma universidade pública do interior paulista, como uma das atividades ligadas à conclusão do processo de estágio. Os relatos mais recorrentes nos portfólios remetem às experiências diretas de ensino vividas no período do estágio. Em seguida, foi possível identificar elementos que se referem à fonte da persuasão social como a segunda fonte mais citada, seguida das experiências vicárias e dos estados fisiológicos e afetivos.

Na subescala Experiências Vicárias, o item que alcançou maior média $(M=5,28)$ entre os participantes foi "- Observar professores habilidosos dando aulas contribui para o que penso sobre minha capacidade para ensinar" (item 2). A fonte de autoeficácia contemplada nessa subescala indica que observar as pessoas que realizam práticas exitosas após esforços perseverantes aumenta as crenças de quem observa. Bandura (1999) afirma que este fato que 
pode implicar no aumento de confiança do observador que também possui capacidades necessárias para realizar atividades semelhantes às observadas. De acordo com Costa Filho (2014), para professores iniciantes, as experiências vicárias se mostram relevantes, uma vez que ainda têm poucas experiências diretas "disponíveis" para sua avaliação. Alvarenga (2011) reforça a importância dessa fonte na constituição das crenças docentes. Em seu estudo, abordando 253 professores de 27 escolas públicas de Campinas, a Experiência Vicária foi a fonte que os professores mais perceberam como constituinte de suas crenças de autoeficácia, seguida de Persuasão Social e Experiência Vivida.

Na subescala Persuasão Social/Verbal destacam-se dois itens com médias mais altas entre os participantes. O item 11 "Receber comentários dos meus alunos avaliando minha prática docente influencia o que penso na minha capacidade para ensinar" $(M=5,44)$ e o item 15 "Ouvir comentários de pessoas que admiro reconhecendo o meu progresso como professor(a) afeta o que penso sobre minha capacidade para ensinar" $(M=5,28)$. Tais valores de médias indicam que os professore participantes da pesquisa compreendem que sua percepção de autoeficácia é aumentada quando são elogiados por seus alunos e por outros profissionais que admiram. No caso dos participantes do estudo de Costa Filho (2014), percebe-se, em seus relatos, que sua autoavaliação é baseada nos feedbacks e participação dos alunos, denotando que os alunos têm grande influência na percepção de capacidade dos professores.

Embora os participantes desse estudo tenham tido as menores médias nessa subescala, da mesma forma encontrada em outros estudos como de laochite (2007), onde em relação à distribuição de respostas dos participantes para cada item apresentado observou-se que aqueles relacionados com os Estados fisiológicos e afetivos apresentaram os valores mais baixos. Convém esclarecer que o item que consideraram como mais influente na sua percepção de autoeficácia foi referente a mudanças no estado de humor durante a sua prática. Indicaram que essas mudanças de humor afetam o que pensam sobre sua capacidade para ensinar.

\section{CONCLUSÃO}

Para o presente estudo, os resultados indicaram que, entre os professores participantes, as fontes Persuasão Social $(M=25,6)$ e Estados Fisiológicos e Afetivos $(M=17,5)$ são mais determinantes na formação das crenças de autoeficácia, seguidos de Experiências Vicárias $(M=15,2)$ e Experiências Vividas ( $M=14,6)$.

Isso revela que para os professores da amostra, entre as quatro fontes, importa mais o feedback que recebem em relação ao seu trabalho quando se referem a percepção da autoeficácia do que as experiências vivenciadas. Também consideraram como influente na sua percepção de autoeficácia as mudanças no estado de humor durante a sua prática, indicando que essas mudanças de humor afetam o que pensam sobre sua capacidade para ensinar. Sugerem-se novos estudos, pois a investigação sobre as fontes de constituição da crença de autoeficácia de professores é recente, e a escassez da produção se constitui em motivação para a realização de pesquisas mais aprofundadas afim de investigar, junto aos docentes, as fontes formadoras das suas crenças de autoeficácia.

\section{REFERÊNCIAS}

ALVARENGA, C. E. A.. Autoeficácia de professores para utilizarem tecnologias de informática no ensino. (Tese de Doutorado). Faculdade de Educação, Universidade Estadual de Campinas, Campinas, Brasil. 2011.

BANDURA, A. Self-efficacy: The exercise of control. New York: W. H. Freeman and Company. 1997. 
BANDURA, A. Ejercicio de La eficácia personal y colectiva em sociedades cambiantes. Em A. Bandura (Ed.), Auto-Eficacia: como afrontamos los câmbios de la sociedad actual. (19-54). Espanha: Bilbioteca de Psicologia Desclée de Brouwer. 1999.

COSTA FILHO, R. A. Professores iniciantes de educação física: discussões a partir das fontes de autoeficácia docente. (Dissertação de Mestrado). Instituto de Biociências do Campus de Rio Claro, Universidade Estadual Paulista "Júlio de Mesquita Filho", Rio Claro, Brasil. 2014.

COSTA FILHO, R. A., IAOCHITE, R. T. Experiências de ensino no estágio supervisionado e autoeficácia para ensinar educação física na escola. Revista Educação Física/UEM, v. 26, n. 2, 201211. 2015.

FERREIRA,L. C. M., AZZI, R. G. Docência, burnout e considerações da teoria da auto-eficácia. Psicol. Ensino \& Form. vol.1, n.2 , 23-34. 2010

IAOCHITE, R. T. Auto-Eficácia de Docentes de Educação Física. (Tese de Doutorado). Faculdade de Educação, Universidade Estadual de Campinas, Campinas, Brasil.2007.

IAOCHITE, R. T.I; AZZI, R. G. Escala de fontes de autoeficácia docente: Estudo exploratório com professores de Educação Física. Psicol. Argum., Curitiba, v. 30, n. 71, 659-669. 2007.

NUNES, M. F. O. .Funcionamento e desenvolvimento das crenças de auto-eficácia: uma revisão. Rev. bras. orientac. prof [online], vol.9, n.1, 29-42.. 2008.

ROCHA, M. S. A. . Autoeficacia Docente no Ensino Superior (Tese de Doutorado). Universidade Estadual de Campinas. Campinas, Brasil.2009. 